University of South Carolina

Scholar Commons

\title{
Mandarin Chinese: An Annotated Bibliography of Self-Study Materials
}

Duncan E. Alford

University of South Carolina - Columbia, alfordd@law.sc.edu

Follow this and additional works at: https://scholarcommons.sc.edu/law_facpub

Part of the Legal Profession Commons, Legal Writing and Research Commons, and the Library and Information Science Commons

\section{Recommended Citation}

Duncan E. Alford, Mandarin Chinese: An Annotated Bibliography of Self-Study Materials, 35 Int'I J. Legal Info. 537 (2007)

This Article is brought to you by the Law School at Scholar Commons. It has been accepted for inclusion in Faculty Publications by an authorized administrator of Scholar Commons. For more information, please contact digres@mailbox.sc.edu. 


\title{
Mandarin Chinese: An Annotated Bibliography of Self- Study Materials
}

\author{
DUNCAN E. ALFORD
}

The People's Republic of China is currently the seventh largest economy in the world and is projected to be the largest economy by 2050 . Commensurate with its growing economic power, the PRC is using its political power more frequently on the world stage. As a result of these changes, interest in China and its legal system is growing among attorneys and academics. International law librarians similarly are seeing more researchers interested in China, its laws and economy. The principal language of China, Mandarin Chinese, is considered a difficult language to learn. The Foreign Service Institute has rated Mandarin as "exceptionally difficult for English speakers to learn." Busy professionals such as law librarians find it very difficult to learn additional languages despite their usefulness in their careers.

I have drafted this annotated bibliography of self-study materials on Mandarin Chinese for the busy international law librarian. While a formal language course may not be possible, some time for self-study may be available. The materials in this bibliography were identified for their usefulness to the self-learner of Mandarin. I have organized the bibliography into the following sections:

- $\quad$ Core Titles - print materials that are particularly useful to the beginning self-learner of Mandarin Chinese;

- $\quad$ Other Titles - print materials useful to the self-learner but which may be more beneficial to the intermediate learner or are less effective beginner's materials;

- Interesting Finds - unusual books on the Chinese language that are not particularly useful for the self-learner but would likely be of interest to the student of Chinese. Some are simply fun to read.;

- Characters - print materials that are primarily useful in the self-study of Chinese characters rather than spoken Mandarin;

- Dictionaries and Phrasebooks - Because Chinese is an ideographic language, Chinese dictionaries come in various forms; 
- $\quad$ Beginning Readers - simple readers for the self-learner;

- $\quad$ Readers - readers for the more advanced student;

- $\quad$ Self-Assessment - recommended tests for the self-learner in order to track progress in learning Mandarin;

- Internet Sources - a very selective list of web sites useful in the study of Mandarin;

- $\quad$ Language Software - a very selective list of software programs designed to assist the self-learner of Mandarin;

- $\quad$ Publishers - a list of publishers specializing in study materials for Mandarin Chinese; and

- $\quad$ Recommended Titles - a suggested core set of materials for the Mandarin self-learner. These titles are marked with "Recommended" in bold.

\section{CORE TITLES}

Wendy Abraham, Chinese for Dummies (Hoboken, NJ: Wiley Publishing, Inc., 2005), p. 361. Part of the Dummies series, this book lays out basic Mandarin Chinese in digestible chunks. A major weakness is the failure to introduce Chinese characters. The book includes a $C D$ in order to practice listening.

Wendy Abraham, Chinese Phrases for Dummies (Hoboken, NJ: Wiley Publishing, Inc., 2005), p. 206. The first two chapters of this book describe the basics of Mandarin Chinese. The remaining chapters depict language used in common situations and can be reviewed in any order. The last two chapters list favorite Chinese expressions and phrases that make the speaker "sound like a native speaker."

Elinor Greenwood, Get Talking Chinese: Mandarin Chinese for Beginners (London: Dorling Kindersley Limited, 2007) p. 128. This simply written, amply illustrated book provides a quick introduction to both spoken Chinese and Chinese characters. The nine chapters focus on common situations; chapter 1 is a simple, straight forward introduction to Mandarin Chinese. The accompanying audio CD is best used with the book.

Ping-gam Go, Understanding Chinese Characters by Means of Their Ancestral Forms (San Francisco: Simplex Publications, 1989), p. 100+. A type of dictionary, this book uses Wade-Giles romanization and traditional characters and includes the text $A$ Walk through Chinatown in San Francisco.

Yong Ho, Chinese-English Frequency Dictionary: A Study Guide to Mandarin Chinese's 500 Most Frequently Used Words (New York: 
Hippocrene Books, Inc., 2002), p. 240. This dictionary lists Chinese characters in order of frequency of use. The dictionary provides multiple meanings of the character and then gives examples of its use in both simplified characters and pinyin. Includes an index of the characters in order of frequency and alphabetically by pinyin. Recommended.

Yong Ho, Beginner's Chinese (New York, N.Y.: Hippocrene Books, Inc., 1997), p. 173. An excellent book for learning to read and write Mandarin Chinese. The book consists of 10 lessons dealing with practical topics. Each lesson consists of written dialog in Chinese characters, pinyin, and English, vocabulary lists, language notes (very useful and understandable commentary on grammar and language use), exercises and cultural insights. The cultural insight at the end of each lesson was a pleasure to read and gave cultural context to some portion of the previous lesson. Includes a glossary, bibliography and Wade-Giles to Pinyin Cross-Reference Table. Highly recommended. The only criticism is that there are several typographical errors in the text and that the answer key does not contain answers to all the exercises in the book. Recommended.

Philip Yungkin Lee, A Chinese Character a Day, vol. 1 (Rutland, VT: Tuttle Publishing, 2005), p. 365 . This book is in actuality a stack of 365 characters designed for the learner to review each day. Each page includes a character, its pinyin, its stroke order, four examples of usage and space to practice writing the character.

Philip Yungkin Lee, A Chinese Character a Day, vol. 2 (Rutland, VT: Tuttle Publishing, 2006), p. 365. This book is a second stack of 365 characters designed for the learner to review each day. Each page includes a character, its pinyin, its stroke order, four examples of usage and space to practice writing the character.

Philip Yungkin Lee, 250 Essential Chinese Characters for Everyday Use, vol. 1 (Rutland, VT: Tuttle Publishing, 2003), p. 338. This volume contains 250 commonly used characters. One page for each character contains the character, notes on its pronunciation, the radical of the character, compounds and sentences using the character, and a grid for practicing. The book is divided into 25 units of 10 characters each with review tests at the end of each unit. A fifteen-page introduction describes the basic strokes, stroke order, simplified versus traditional characters, pinyin and tones. Alphabetical index by pinyin; radical index. Recommended. 
Philip Yungkin Lee, 250 Essential Chinese Characters for Everyday Use, vol. 2 (Rutland, VT: Tuttle Publishing, 2004), p. 344. A second volume containing 250 commonly used characters. One page for each character contains examples, information on the character and a grid for practicing. Review tests are included. Alphabetical index by pinyin; radical index.

\section{Recommended.}

Philip Yungkin Lee, Chinese in a Flash, vol. 1 (Rutland, VT: Tuttle Publishing, 2003), p. 500+. This boxed set of 448 cards contains the characters in the same order as the two volumes of 250 Essential Chinese Characters for Everyday Use. On the front of each card is the character in both its simplified and traditional forms with four compound word examples. On the reverse is the character, its pinyin romanization, the associated radical, an example sentence and the pinyin and English meaning of the four compound word examples. The accompanying booklet contains an alphabetical pinyin index and stroke order index of the 500 characters.

Philip Yungkin Lee, Chinese in a Flash, vol. 2 (Rutland, VT: Tuttle Publishing, 2004), p. 500+. This boxed set contains another 448 commonly used characters and is the companion set to Chinese in a Flash, volume 1. On the front of each card is the character in both its simplified and traditional forms with four compound word examples. On the reverse is the character, its pinyin romanization, the associated radical, an example sentence and the pinyin and English meaning of the four compound word examples. The accompanying booklet contains an alphabetical pinyin index and stroke order index of the 500 characters.

Walter Long, Fingertip Chinese: Get to Know the Real China (New York: Weatherhill, Inc., 1996), p. 198. I usually try to avoid small phrasebooks of foreign languages because I find them too simplistic and therefore not very enlightening. This book is different. While small in size like a phrasebook, it is drafted for practical use and each chapter is centered on a particular social situation such as "Getting Acquainted" and "Getting Fed." The book provides English phrases with both pinyin and Simplified Chinese character translations. At the end of the book is a list of lists which serves as an index of the major topics covered in this small, thin volume.

Alison \& Lawrence Matthews, The First 100 Chinese Characters (North Clarendon, VT: Tuttle Publishing, 2006), p. 128. This thin volume lists 100 common characters with one character per page and a grid for practicing writing the Character. A short introduction gives background on Chinese 
characters and suggested methods for practice. Table of Contents; Hanyu Pinyin index; radical index; English-Chinese index. Recommended.

Alison \& Lawrence Matthews, The Second 100 Chinese Characters (North Clarendon, VT: Tuttle Publishing, 2007), p. 128. This thin volume lists another set of 100 common characters with one character per page and a grid for practicing writing the character. A short introduction gives background on Chinese characters and suggested methods for practice. Table of Contents; Hanyu Pinyin index; radical index; English-Chinese index. Recommended.

Richard Newnham, About Chinese, Revised Edition (Middlesex, Eng.: Penguin Books, 1987), p. 189. This book is an "introduction to the Chinese language for non-learners." It operates at three levels according to the author. First, it will satisfy the curiosity of the beginning learner. For readers who want to be students, the book provides an approach to learning. For current students of Chinese, this book is a guide whenever other books or texts are not meeting the student's needs. According to the author, the nonstudent should read Chapters 1 through 5 . The potential student of Chinese should focus on Chapter 6. The current student should focus on Chapters 6 and the later chapters. In my view, the books do provide a general background and some discussion of the grammar and syntax of Mandarin Chinese. The author lauds Chapter 6 entitled "Functions" as central to the book. While it does give good insights to the differences between Mandarin Chinese and English, I found the chapter difficult to follow. It goes over the grammar basics. However, the chapter is straight text with little breaks in the format to provide digestible pieces. I found the use of pinyin, Chinese characters and the English translations in straight text difficult to follow. It would have been easier to follow if the author had broken up the sample sentences into a more comparative format with the Chinese characters on one line, the pinyin on the next line and the English translation on the following line. Chapter 10 is a brief, succinct guide to stroke order in writing characters with 50 different examples. Chapter 12 provides one of the best comparisons of the various romanization methods I have seen with logical advice to students on which romanization to learn. The author not surprisingly recommends pinyin. The last portion of the book is an annotated bibliography of additional books recommended for learning Mandarin Chinese. Given the date of this book, most of the recommended books are out of print but can be located at a good research library.

Tan Huay Peng, Fun with Chinese Characters, vol. 2, North American Edition ed. (New York: Infini Press, 2003), p. 153. This entertaining book describes 153 common characters. Each single page entry for the character 
includes the simplified and traditional character, pinyin, English meaning, stroke order, examples of words using the character, and an example sentence. Peng, a cartoonist for The Straits Times in Singapore, uses his clever cartoons to illustrate the character and its meaning.

Tan Huay Peng, Fun with Chinese Characters, vol. 3, North American Edition ed. (New York: Infini Press, 2003), p. 145. This companion book to Peng's series describes 140 common characters. Each single page entry for the character includes the simplified and traditional character, pinyin, English meaning, stroke order, examples of words using the character, and an example sentence. Peng, a cartoonist for The Straits Times in Singapore, uses his clever cartoons to illustrate the character and its meaning.

Claudia Ross, Chinese Grammar (New York: McGraw-Hill, 2004), p. 279. This book, part of the Schaum's Outline series, is intended as a student aid to learning Chinese grammar. The fourteen chapters focus on various aspects of grammar, such as verbs and verb phrases, nouns, prepositions, and questions and question words. Exercises are used throughout. Index.

Elizabeth Scurfield and Song Lianyi, Beginner's Chinese Script: An Introduction to Reading and Writing Chinese (Hodder Headline plc, 1999), p. 180. This self-study book begins with a short history of Chinese writing and then goes right into the rules and method of character writing. Subsequent chapters are centered on everyday situations and the use of characters in those situations. Exercises and review tests are used throughout this book. Includes a list of common signs, Chinese-English vocabulary organized by radical and stroke order and English-Chinese vocabulary ordered alphabetically.

Recommended.

Elizabeth Scurfield and Song Lianyi, Beginner's Chinese: An Easy Introduction (Hodder Headline plc, 1996), p. 267. This book, designed for the self-learner, focuses on everyday situations as the basis for the lessons on listening, speaking and reading pinyin. Chinese characters are introduced in Chapter 11 about half way through the book. The book comes with two cassettes for the listening and speaking exercises. Useful vocabulary list at the end in alphabetical order by pinyin.

Elizabeth Scurfield and Song Lianyi, Beginner's Chinese: A Complete Course for Beginners (Hodder Headline plc, 1991), p. 357. This book, designed for the self-learner, focuses on everyday situations as the basis for the lessons. The program, lengthier than the previous book, focuses on listening, speaking and reading pinyin. Chapters 1 through 11 use pinyin and 
English translation in teaching grammar and vocabulary. Chapter 12 is a concise summary of grammar rules covered previously. Chinese characters are introduced in Chapter 13 about half way through the book. The book comes with two cassettes for the listening and speaking exercises. Exercises are used in each chapter. A character text of the dialogues are at the end of the book with an English index to grammar notes and cultural references as well as a useful vocabulary list in alphabetical order by pinyin and another alphabetical list in English. Recommended.

Julie Mazel Sussman, I Can Read That: A Traveler's Introduction to Chinese Characters (China Books, 1994), p. 161. This popular, non-scholarly book introduces 73 characters commonly seen in mainland China. The author intends to teach the reader to recognize the character with the secondary purpose of teaching how to write the character. Includes a subject index, pinyin index and English index. Recommended.

Diane Wolff, Chinese for Beginners (New York, NY: Barnes and Noble Books, 1985), p. 231. This introduction to Chinese language describes tones and includes a good but brief chapter on Chinese grammar. The second part of book is devoted to a list of most common characters (approx. 150) grouped by category, and includes stroke order, English translation, and romanized Chinese (using Yale romanization). A reprint of An Easy Guide to Everyday Chinese (1974).

Diane Wolff, Chinese Writing: An Introduction (New York: Holt, Rinehart \& Winston, 1975), p. 46. This short history of Chinese writing describes strokes and the importance of stroke order. It introduces about 30 characters with English translation and pinyin romanization and numbers 1 through 10 and the months of the year.

Hong Xiao, Talk Mandarin Today / Jin ri xue shuo Putonghua (Hong Kong: Chinese University Press, 2003), p. 338. This very useful book for the adult self-learner is organized into 30 lessons focused on practical situations such as Business Cards, Day of the Week, Months and Year, Sending a Fax, etc. and introduces 730 characters. Each lesson includes a dialogue, the first in simplified characters, then pinyin, and finally English. The three formats are on the same page but in separate groups. A slightly better format would be to have each line of dialog together in the three formats. A helpful feature is that the characters are in a slightly larger size than a normal publication - very helpful to the beginner deciphering the characters. Includes appendices containing groups of related words such as time words (months, Chinese lunar years) and place words (such as countries and cities) and a Chinese - English 
glossary. The book uses pinyin romanization throughout and introduces characters with the first lesson. There is a separate Character workbook. The author developed this book based on lectures he gave at Trinity University in Dublin and King's College in London. Recommended.

\section{OTHER TITLES}

Harry S. Aldrich, Practical Chinese (New Haven: Department of Oriental Studies, Yale University, 1942), p. 276. The first 40 pages of volume 1 give an analysis and description of the Chinese language. The textbook uses Wade-Giles romanization, and is not designed for the self-learner. A classic text for teaching Chinese as a foreign language. Two volume set.

T. K. Ann, Cracking the Chinese Puzzles: Ann's Integrated Method of Learning the Chinese Language by Conceptualizing and Philosophizing Approach (Hong Kong: Stockflows Co., Ltd., 1982). This set introduces 5,888 characters using traditional characters, simplified characters and pinyin. 5 volume set; Volume 1 - Primer and Singletons, focuses on 170 bushous (also known as radicals); Volume 2 - Differentiation; Volume 3 - You Can Decipher Chinese Puzzles Too; Volume 4 - Antonyms and Some Obvious Patterns; Volume 5 - Appendices. Volume 5 has numerous word lists, such as a List of 3,650 Frequently Used Characters and a List of Characters Indigenous to Hong Kong (many of which will do not appear in the typical Chinese dictionary).

Johan Björkstén, Learn to Write Chinese Characters (New Haven: Yale University Press, 1994), p. 123. This book describes in detail how to write characters correctly; describes each type of stroke in detail, with Chinese name; lists common radicals with stroke order, pinyin romanization, and English translation. A separate section includes a poem and additional characters to practice.

Raymond Chang and Margaret Scrogin Chang, Speaking of Chinese (New York: W.W. Norton \& Company, Inc., 1978), p. 197. Targeted at the general reader interested in the Chinese language, this quick, light, entertaining read focuses more on the history of the language and Chinese culture related to the language. Some characters are introduced but this book is not designed for language instruction. Three appendices contain a chronology of Chinese dynasties, a list of the most common radicals, and a list of the birth years and characteristics of the twelve animal zodiac signs. Short bibliography. No index. 
Wei Chu-Hsien, How to Be Literate in Chinese: An Introduction to the 214 Classifiers of Chinese Thought and Script (Hong Kong: Wei ChuHsien, 1969?), p. 224. This book lists the 214 radicals in order of number of strokes and uses Wade-Giles romanization. At the end of the book is a list of all 214 radicals with characters and Wade-Giles romanization.

Boye Lafayette De Mente, The Chinese Have a Word for It: The Complete Guide to Chinese Thought and Culture (Lincolnwood, Ill.: Passport Books, 2000), p. 506. An alphabetical list of idioms or cultural terms in which each entry contains the character, the pinyin romanization, a pidgin phonic pronunciation, and a 1-2 page definition of the term. The book is more a cultural guide to China than a language guide and gives much more detail and background on the meaning and cultural context of the character than is possible in a dictionary. Previously published in 1996 as NTC's Dictionary of China's Cultural Code Words.

Yu Feng, A Learners' Handbook of Modern Chinese Written Expressions; Hsien tai Han yü shu mien yü hsüeh hsi shou tse (Hong-Kong: Chinese University Press, 1999), p. 168. Written for the advanced student (three years' minimum of study), this readable book's eighteen chapters focus on written expression. Chapter 1 focuses on the abbreviations of multicharacter words. Later chapters focus on reading different types of writing, such as news reports, academic essays, advertisements, and correspondence

Henry C. Fenn, Chinese Characters Easily Confused (New Haven, CT: Institute of Far Eastern Languages, Yale University, 1953), p. 84. This book, an aid to the comparative study of Chinese characters, is not a dictionary. This book organizes easily confused characters into 276 separate groups of two to seven characters each. The beginning student can thus quickly distinguish the most similar characters. A major weakness of this book is the use of the Yale and Wade-Giles romanization, rather than pinyin.

Jiaying Howard, A Student Handbook for Chinese Function Words (Hong Kong: Chinese University of Hong Kong, 2002), p. 305. A handbook on function words -- prepositions, conjunctions, articles, etc. These function words tend to be the most difficult for students of a foreign language to master. Includes approximately 500 regularly used function words listed in alphabetical order by pinyin. Each entry includes the pinyin romanization of the word, Chinese characters, the English definition, the part of speech and several sentences showing its correct use. The sentences are in Chinese characters and pinyin with an English translation. This book would be more useful to the intermediate student because it is a reference work and assumes 
some knowledge of Mandarin. It does not focus on writing characters or stroke order.

Chen Ji, Your First 100 Words in Chinese (Chicago: Passport Books, 1999), p. 70. A basic guide to simple Chinese characters. The characters are introduced in chapters by concept such as Countryside, Animals, etc. The book does not use pinyin for romanization but rather uses a type of pidgin phonetic alphabet. This failure to use an established romanization system is a serious flaw. In the last 6-7 pages of the book are flash cards of the 100 Chinese characters introduced in the book. I found this to be the most useful part of the book - a little expensive for 100 flash cards that do not include pinyin which I added. This book is suggested as a preparation for Read \& Speak Chinese for Beginners by the same publisher. This book was also published under another title The 100 Word Exercise Book Chinese with identical content.

Bernhard Karlgren, Easy Lessons in Chinese Writing (Stockholm: Naturmetodene Sprakinstitut, 1958), p. 173. Karlgren, a prominent Chinese language scholar, drafted this book as a "practical primer," not a treatise. The first part of the book focuses on the 214 traditional radicals; the remainder of the book describes 1044 commonly used characters. For each character, the author provides the character (without stroke order), romanization, English definition, brief etymology and the number of the radical in the character. The romanization is Wade-Giles. Neither pinyin nor simplified characters are used.

George A. Kennedy, Minimum Vocabularies of Written Chinese (New Haven: Sinological Seminar, Yale University, 1954), p. 42. A short booklet that includes a list of common Chinese characters to be used as a minimum vocabulary list for the non-Chinese student. The booklet contains three lists: (1) 1020 List used by Yale in teaching Chinese; (2) list of the 420 most frequently used characters in the works by Mencius, typically used in classical literature; and (3) official list of 2421 characters used in adult education in China. This final list is further divided into four groups based on frequency of use.

Kristine Kershul, Chinese in 10 Minutes a Day (Seattle, WA: Bilingual Books, Inc., 2003), p. 132. A workbook to learn Chinese that includes frequent illustrations, exercises, and flash cards. This book uses very few characters and focuses on pinyin. 
Marjorie Lin and Schalk Leonard, Dictionary of 1000 Chinese Proverbs (New York: Hippocrene Books, 2002), p. 200. The authors have selected 1000 significant Chinese proverbs. The main portion of the dictionary contains the proverb in pinyin with an English translation. The dictionary is organized by radical. At the end of the book is the proverb written in characters. English key word index.

Wendy Lin, Practical Chinese: The Effective Way of Learning, Reading, Writing, and Speaking Chinese, For Beginners, Level II (Matawan, NJ: Creative World Ent., Inc., 2002), p. 76. This workbook uses characters, pinyin, and English translations and includes exercises throughout. This book is part of a larger series that includes two beginners' books and a book for Level I through Level VIII. The series is designed for young native speakers of English, principally children.

Cheng Ma, Read \& Speak Chinese for Beginners (Chicago: McGrawHill, 2004), p. 112. This book introduces basic Chinese characters and uses pinyin for romanization. Exercises throughout the book are useful. Includes flash cards at the end of the book and a CD-ROM. I noted some errors using pinyin and some internal inconsistencies within the book; some flash cards at the end were incorrect. On the whole, it is a useful self-teaching tool but it needs a good copy editor to improve.

John Marney, Chinese by Numbers - First Semester (Ann Arbor: University of Michigan Press, 1997), p. 186. This is the first of four books presenting a two year, four semester program of elementary Mandarin Chinese. I found the "Character Roundup" pages the most useful. Each table shows the Chinese character, the equivalent pinyin and the English translation along with the stroke order of writing the character.

John S. Montanaro and Xiabo Yu, Chinese Vocabulary Cards (Springfield, OH: Visual Education, 1997) p. 1000+. This flashcard set covers 1000 Chinese characters with a total vocabulary of over 3000 characters by virtue of the examples on the cards. The front of each card contains the character, its pinyin romanization, five compound words, each compound's pinyin, and the object of speech of each word. The reverse of the card gives the English translation of each element. The accompanying booklet contains an alphabetical pinyin index of each character and compound word and an alphabetical English index of each word on the cards. The characters on these cards are somewhat smaller than the characters on the Chinese in a Flash sets so they are a little more difficult for the beginner to read. 
D. M. Murray and T. W. Wong, Noodle Words: An Introduction to Chinese and Japanese Characters (Charles E. Tuttle Company, 1987), p. 95. This non-scholarly book introduces Chinese characters through stories about the character's formation. A major weakness is the absence of romanization except in a list of common radicals at the end of the book.

Tan Huay Peng, Chinese Radicals, vol. 2 (Torrance, CA: Heian International, Inc., 1999), p. 136. This book along with its companion volume 1 discusses the 214 radical characters used in written Chinese. Each radical receives two pages describing the radical and common characters that use the radical. Clever cartoons illustrate the meaning. Volume 2 deals with "artifacts and implements of man, his actions and characteristics, and finally, numerals and basic strokes." The companion volume 1 "deals with those radicals that fall under the classification of man, animal, plant and nature."

Tan Huay Peng, Chinese Idioms, vol. 2 (Torrance, CA: Heian International, Inc., 1999), p. 144. This companion volume to Chinese Idioms vol. 1 lists common idioms. Each entry for the idiom is a page long that includes the Chinese characters, the corresponding pinyin, the literal meaning, the actual meaning, an example using the idiom, a synonym and on occasion the origin of the idiom and an antonym. As in the other books authored by Peng, clever cartoons illustrate the idioms. Towards the end of the book are a Hanyu Pinyin index of the idioms and a classified index by subject matter in English.

Tan Huay Peng, Simplified Chinese Characters (Torrance, CA: Heian International, Inc., 1997), p. 128. This book describes the simplification principles used in changing traditional characters to the simplified characters. Clever cartoons illustrate the principles. Towards the end of the book is a Hanyu Pinyin List of Simplified and Regular Characters.

Tan Huay Peng, Hanyu Pinyin (Torrance, CA: Heian International, Inc., 1997), p. 96. This slim volume teaches the sounds of pinyin using Peng's cartoons. Each sound of pinyin is described on a single page with ten examples using the sound, showing the Chinese characters, pinyin, and English translation. A short introduction briefly explains the pinyin system and a vocabulary list at the end organized alphabetically by pinyin serves as an index to this volume.

Clifford H. Phillips, China Beckons: An Insight to the Culture and National Language (Edmonton, Canada: University of Alberta Press, 1993), p. 324. Designed for business travelers and professionals who wish to converse 
during trips to China, this book uses common situations as the basis for its lessons. A significant weakness is the failure to introduce Chinese characters in the book. An appendix lists key characteristics of Mandarin Chinese (numbers, measure words, comparisons, etc.). This book is divided into two parts: the first on "Practical Instructions on Learning Chinese" and the second a series of 15 chapters with dialogues. Not recommended for those who want to learn to read Chinese characters.

Shou-he Tian, A Guide to Proper Usage of Spoken Chinese = Han yu kou yu zhi yin, Second ed. (Shatin, N.T., Hong Kong: Chinese University Press, 1992), p. 196. This reference book is intended to accompany elementary Chinese textbooks. The author has identified 104 points of grammar or vocabulary that have caused students problems with elementary Chinese. They are listed here in alphabetical order by pinyin with an explanation and examples for each entry. There is a list of all entries at the beginning of the book and a more detailed index at the end.

P. C. Tung and H. D. R. Baker, Chinese in Three Months (New York: DK Publishing, 1999), p. 303. This book on teaching oneself conversational Mandarin Chinese focuses on pronunciation and understanding of simple conversations. Chapter 20 introduces Chinese writing and includes 2 pages of characters with pinyin romanization and English translation commonly used by business travelers.

Fang-yu Wang, Read Chinese: A Beginning Text in the Chinese Character, Expanded Edition ed. (New Haven: Far Eastern Publications, Yale University, 1982), p. 236. This book is the companion reader to M.G. Tewksbury's Speak Chinese published by the Institute of Far Eastern Languages at Yale University. The author recommends that the student complete the first 12 chapters of Speak Chinese prior to studying this text. This first book in a three book series entitled Read Chinese introduces 300 characters to students. The lessons begin with a mix of Chinese characters and romanization with the percentage of characters increasing with each lesson. Book I was originally published in 1953. This 1982 expanded edition uses simplified characters and pinyin romanization. The introduction gives a brief overview of the parts of speech and Chinese grammar. At the end is a list of the 300 characters introduced by number of strokes and then a separate list showing the stroke order for each of the 300 characters. Finally, there is a glossary in alphabetical order by pinyin romanization. The foreword to the expanded edition stated that pinyin romanization was used in this edition, but Yale romanization predominates in the book. I chose not to use this book for self-study because it does NOT use pinyin romanization. 
Julian Wheatley, Learning Chinese: A Foundation Course in Mandarin, Part I (Boston: MIT Open Courseware, 2005), p. 209. The textbook for the elementary Chinese course at MIT is part of MIT's ambitious Open Courseware site. The textbook follows along with the course and it is not strictly designed as a stand-alone self-teaching text. Nevertheless, the textbook is a good reference source for the self-learner. It emphasizes traditional characters but also includes simplified characters. Recommended.

Kenneth Wilkinson, Chinese Language, Life and Culture (Chicago: McGraw-Hill, 2002), p. 235. A quick read, this book focuses on culture and history with some Chinese characters and pinyin of relevant terms. Not very useful for learning Mandarin, but a useful overview of Chinese history and culture. At the end of each chapter, the author makes suggestions for additional reading.

Boping Yuan and Kan Qian, Developing Writing Skills in Chinese (New York: Routledge, 2003), p. 204. A practical guide to writing Chinese characters for the intermediate learner, this book includes chapters on writing cards, business correspondence, reports, and job applications as well as chapters on describing places, the weather, physical attributes, etc. Recommended for the advanced learner who needs assistance in writing in everyday situations. Includes Chinese-English glossary.

\section{INTERESTING FINDS}

John DeFrancis, The Chinese Language: Fact and Fantasy (Honolulu: University of Hawaii Press, 1984), p. 330. A scholarly book debunking the myths surrounding the Chinese language such as that characters are the same in Japanese, Chinese and Vietnamese languages. The book did not help with learning Chinese characters but did provide detailed background on the development of the Chinese language and the "aura" surrounding the Chinese language and its written characters.

Ezra Pound and Ernest Francisco Fenollosa, Instigations of Ezra Pound : Together with an Essay on the Chinese Written Character, Essay Index Reprint Series, Books for Libraries Press, Inc. 1967 ed. (New York: Boni and Liveright, 1920), p. 388. In the essay, The Chinese Written Character, edited by Ezra Pound, Ernest Fenollosa argues that the Chinese written language has maintained its poetic character more so than other phonetic languages. 
Russell Jones, Chinese Names: The Use and Meanings of Chinese Surnames and Personal Names in Singapore and Malaysia (Malaysia: Pelanduk Publications, 1989), p. 84. A detailed discussion of Chinese surnames uses Wade-Giles romanization and provides pronunciation in Mandarin and Hokkien dialects with some Cantonese pronunciations. An interesting chapter on Chinese seals for writing gives details on the order of characters on the seal. Includes a list of common surnames arranged by stroke order and a list of Western names using Chinese characters.

James D. McCawley, The Eater's Guide to Chinese Characters (Chicago: University of Chicago Press, 1984), p. 248. This entertaining book is intended to empower the reader to decipher a Chinese menu. Half the book consists of a glossary of words for Chinese food and an English index of words describing Chinese food.

Lee Kuan Yew and Chee Lay Chua, Keeping My Mandarin Alive (Singapore: Global Publishing Co., 2005), p. 241. This memoir by the former Prime Minister of Singapore, Lee Yuan Kew, focuses on his study of Mandarin Chinese and the maintenance of his Mandarin language skills. While not useful in learning Mandarin, it does provide insight into one adult's method of learning Mandarin Chinese and suggested learning techniques. Includes a DVD.

A. Zee, Swallowing Clouds: A Whimsical Look at Chinese Food (New York: Simon and Schuster, 1990), p. 378. This book is mainly in English but incorporates Chinese characters with stories explaining their meaning. Fun to read, this book emphasizes Cantonese food and uses traditional characters. List of characters discussed at the end of the book. The author, a physicist at UC-Santa Barbara, grew up in Hong Kong.

\section{CHARACTERS}

Barbara Aria, The Nature of the Chinese Character: Gifts from the Earth (San Francisco, CA: Chronicle Books, LLC, 2001), p. 95. This short book introduces 39 characters related to the earth and nature. Each entry shows the character, stroke order, pinyin and an explanation of the meaning of the character. This book is more of a "coffee table" book than a self-study language book, but does provide a short character review.

Barbara Aria, The Spirit of the Chinese Character: Gifts from the Heart (San Francisco, CA: Chronicle Books, LLC, 1992), p. 96. This short 
book introduces 40 characters related to emotion and human qualities. Each entry shows the character, stroke order, pinyin and an explanation of the meaning of the character. This book, the predecessor to The Nature of the Chinese Character, is more of a "coffee table" book than a self-study language book, but does provide a character review.

Huoping Chen, What's in a Chinese Character / Qu wei Han zi, (Beijing: Xin shi jie chu ban she, 1999), p. 185. This book begins with an introduction that describes the rules for writing Chinese characters and the history of Chinese characters. Using cartoons, the author introduces 369 commonly used characters. Each page contains entries for two characters. Each entry contains the character, the English translation(s), stroke order, examples using the character with the pinyin and English translations, and several cartoons depicting the character and its meaning. Pinyin index.

Rita Mei-Wah Choy, Read and Write Chinese : A Simplified Guide to the Chinese Characters, 2d ed. (San Francisco, Calif.: Choy, 1979), p. 310. A dictionary of 3200 characters. For each character, the author provides step by step instructions on writing the character, its English translation, its Cantonese pronunciation using Yale romanization, and its Mandarin pronunciation using pinyin romanization. Character index by frequency of use; comprehensive character index, Mandarin pinyin index, English index.

Chan Kwok Kin and William Crewe, Learn Chinese Characters in Hong Kong, 3rd ed. (Hong Kong: Greenwood Press, 2000), p. 180. This short book uses signs in Hong Kong to illustrate 120 common Chinese characters. Each page contains a character, its Cantonese transliteration, English translation, stroke order, photograph of a sign using the character, examples of words using the character, and the Yale, Lau, and pinyin romanization of the character and word examples. Includes a list of characters by stroke order and the names of major buildings, hospitals, streets and other landmarks in Hong Kong in Chinese characters with romanization.

John DeFrancis, Character Text for Beginning Chinese, 2nd ed. (New Haven: Yale University Press, 1976), p. 519. Part of Yale Language Series, this book contains definitions of 494 characters plus 14 characters added in this second edition. The book uses traditional and simplified characters and pinyin romanization.

Edoardo Fazzioli and Rebecca Hon Ko, Chinese Calligraphy : From Pictograph to Ideogram : The History of 214 Essential Chinese/Japanese Characters (New York: Abbeville Press, 1987), p. 251. This book displays 
each Chinese character on a single page and shows the historical development of the character. Each entry includes the stroke order, the simplified character, if any, and a textual description on how to write the character and its history.

T. C. Lai, Chinese Characters (Kowloon, Hong Kong: Swindon Book Co., 1980), p. 97. This book collects characters with pinyin romanization and original ideograms grouped in broad subject category. Each entry includes the character in various scripts (cursive, clerical), its pinyin romanization, its English definition, and an explanation of character.

Sukming Lo, Picture Chinese: Art As Language (South San Francisco, California: Long River Press 2006), p. 325. This colorfully illustrated book describes 108 common Chinese characters. Each entry includes the character's ancient, present and simplified form, an analysis of the character's components, and its pinyin pronunciation.

William McNaughton, Reading and Writing Chinese : A Guide to the Chinese Writing System, (Rutland, Vt.: Tuttle, 1979), p. 376. This revised edition describes how to write 1,062 of the most commonly used Chinese characters. Five characters are presented on each page with each entry containing the character, its stroke order, its pinyin, its English meaning and a textual explanation on how to write the character. The introductory student's guide describes the history of Chinese writing, the importance of stroke order in writing characters, and the pronunciation of Mandarin Chinese. Includes an alphabetical index of the pinyin and a stroke count - stroke order index. Recommended.

Rose Quong, Chinese Written Characters: Their Wit and Wisdom (Boston, Mass.: Beacon Press, 1973), p. 78. This slender volume uses poems and quotations to illustrate Chinese characters. While it is not very useful for learning new characters because the characters are not clearly drawn, it is an entertaining read once you know a few characters. Principally in English with Chinese characters and pinyin romanization.

Nancy N. Seymour, How to Identify Chinese Characters (Metuchen, N.J.: Scarecrow Press, 1989), p. 427. The goal of this book is to enable a reader to identify and transcribe Chinese characters into pinyin. The book lists 4000 of the most common characters, and includes a Wade-Giles, Yale, pinyin romanization comparison chart in appendix II, and a bibliography in appendix III. 
Ed Young, Voices of the Heart (New York: Scholastic Press, 1997), p. $60+$. Lists 26 characters that use the radical for heart. The main purpose of the book is NOT to teach Chinese characters but rather to explore the meanings of these emotions. Beautifully illustrated.

\section{DICTIONARIES AND PHRASEBOOKS}

Oxford Starter Chinese Dictionary (Oxford, United Kingdom: Oxford University Press, 2000), p. 450. The first part of this useful beginner's dictionary is organized alphabetically by pinyin; the second part is organized alphabetically by English word. The short introduction on the Chinese language is helpful as is a seven page section listing basic measure words. Recommended.

Mandarin Chinese Dictionary Phrasebook (London: Penguin Books, 1999), p. 288. This pocket-sized book starts with a 46 page introduction to Chinese grammar and common phrases. The bulk of the book is the typical English-Chinese and Chinese-English dictionary. The book ends with useful sections on common signs and a menu reader.

Boye Lafayette De Mente, Survival Chinese (Rutland, VT: Tuttle Publishing, 2004), p. 158. This phrasebook provides commonly used sentences in pinyin with Chinese characters and the English translation.

Boye Lafayette De Mente, Instant Chinese (Rutland, VT: Tuttle Publishing, 2004), p. 123. This phrasebook is organized around 100 common topics. Each phrase includes pinyin with phonetic pronunciation, Chinese characters and the English translation.

Ping-gam Go, What Character is That? An Easy-Access Dictionary of Five Thousand Chinese Characters, 2nd ed. (San Francisco: Simplex Publications, 1995), p. 200+ This dictionary of 5,000 Chinese characters helps the reader identify the meaning of the Chinese character. The reader uses this dictionary to locate the English meaning of a character. The author first describes the system of radicals and then organizes the characters by the English name of the radical.

Guangdong: Preparing for the WTO Challenge (Hong Kong: Chinese University Press, 2003), p. 358. This book is a series of essays on the economic development of Guangdong. Pages 353-357 contain a glossary of terms related to Guangdong's economy in alphabetical order in English with 
Chinese characters. Includes specific terms such as "Guangzhou Paper Company Ltd."

Rick Harbaugh, Chinese Characters: A Genealogy and Dictionary (Taipei: Zhongwen.com, 1998), p. 400+. This unusual dictionary is very useful in learning about the relationship of characters. The dictionary includes an English index and pinyin index. These indexes refer the reader to the appropriate section of the genealogy tables - the substance of this dictionary. The author has organized related characters into a genealogy. While the reader can locate the characters and English translation easily, the great value of this dictionary is relating the characters to each other and allowing the reader to learn about "related" characters as well as the particular character the reader was seeking. A scholarly, but useful tool for the beginner. Recommended.

Fredric M. Kaplan and de Keijzer, Arne J., The China Guidebook (New York: Eurasia Press, 1984), p. 629+. Travel guidebook organized by city. Glossary of Chinese Place Names with Wade-Giles romanization, Pinyin romanization and Chinese characters (p. 608-10), Chinese Language Guide (p. 597+)

Dong Li, Beginner's Chinese Dictionary, First ed. (Rutland, VT: Tuttle Publishing, 2004), p. 204. A concise beginner's dictionary. The introductory pages contain notes on pronunciation, grammar, and the writing of characters. Alphabetical entries cover approximately 1,033 words required for Level A of the HSK test. Includes radical index, stroke index, EnglishChinese word finder list, measure word list, and a useful word list. The author is a senior lecturer at Massey University, New Zealand.

Lawrence Matthews, Chinese Character Fast Finder (Rutland, VT: Tuttle Publishing, 2004), p. 200+. This book is used to find the meaning of a Chinese character. The reader looks up an unfamiliar Chinese character by looking for the radical and then finding that section of the book. This book is the reverse of the typical English-Chinese dictionary. Rather than starting with an English word looking for the Chinese character, this book is used when the reader has an unfamiliar Chinese character and is looking for its English meaning.

E. C. Parnwell, New Oxford Picture Dictionary, English / Chinese edition ed. (Oxford: Oxford University Press, 1989), p. 124. This dictionary of approximately 2400 words is primarily aimed at Chinese speakers learning English. Each page has a picture of a related group of items with English 
word and Chinese characters. Two weaknesses are no pinyin romanization and the small font size of the Chinese characters.

Ann Rayson, Chinese Word Book (Honolulu: The Bess Press, 1990), p. 95. This book is an illustrated dictionary organized by topic. The approximately 200 words are illustrated with a black and white line drawing and each word entry includes the pinyin romanization, English translation, simplified character and traditional character. Also includes a glossary ordered alphabetically by pinyin and English translation.

Times English Chinese Pinyin Dictionary (Hong Kong: Federal Publications, 1988), p. 243. This dictionary provides entries for English words; despite its title there is no section organized by pinyin. Each entry of the English word includes a phonetic English pronunciation, Chinese characters using simplified characters and the pinyin romanization. An interesting table at the end of the book is a brief chronology of Chinese history organized by Chinese dynasty.

SAR

Legal Glossary, Bilingual Legal Information System, Hong Kong

http://www.legislation.gov.hk/eng/glossary/index.htm

This online dictionary of legal terms is available in an EnglishChinese version and Chinese-English version. From this same web site, the student or researcher can access a separate glossary of terms used in electoral legislation in Hong Kong. Recommended.

Master List of Chinese Characters

This online dictionary is part of a larger website managed by a freelance web programmer, Adam Sheik, out of the United Kingdom. The online dictionary is an English - Cantonese - Mandarin dictionary and is edited by several dozen volunteer editors.

http://www.cantonese.sheik.co.uk/scripts/masterlist.htm

\section{BEGINNING READERS}

Yung Teng Chia-yee, The Herd Boy and the Weaving Maid (Honolulu: University Press of Hawaii, 1975), p. 43. This simplified retelling of a Chinese fable is intended as supplementary reading after completing the first 30 lessons of Beginning Chinese Reader by DeFrancis; uses 250 characters and an additional 33 characters needed to tell the story; includes notes, stroke order table, pinyin index. 
Peggy Goldstein, Long is a Dragon: Chinese Writing for Children (Berkeley, Calif.: Pacific View Press, 1992), p. 30. This children's book on Chinese writing goes through simple characters (about 40) and numbers 1 through 10 including the stroke order of the Chinese character, English translation and pinyin translation. No index.

Maywan Shen Krach, D is for Doufu: An Alphabet Book of Chinese Culture (Arcadia, CA: Shen's Books, 1997), p. 32. This short book designed for the young reader introduces a character for each letter of the alphabet. Each page includes the character, its pinyin and a brief textual entry describing its meaning. This book is more interesting for students who have already have some knowledge of simple Chinese characters. A Companion Book includes common characters, flash cards and various exercises to assist in learning characters.

Huy Voun Lee, 1, 2, 3, Go! (New York: Henry Holt and Company, 2000). Principally in English, this children's book introduces 23 characters including the numbers one through ten.

Huy Voun Lee, In the Park (New York: Henry Holt and Company, 1998). Mainly in English, this children's book introduces ten Chinese characters.

Huy Voun Lee, In the Snow (New York: Henry Holt and Company, 1995). This children's book introduces 10 characters related to snow.

Huy Voun Lee, At the Beach (New York: Henry Holt and Company, 1994). This children's book introduces 10 characters related to the beach.

John Lewis, The Chinese Word for Horse and Other Stories (New York: Schocken Books, 1980). These three children's stories in English incorporate about 20 Chinese characters both graphically and in the story line. No romanization.

Leong Va, A Letter to the King (New York: Harper Collins, 1987), p. 31. This juvenile story is told in English with Chinese characters on each page. The focus of the book is on the story, not learning the Chinese characters. The Chinese characters paraphrase the English text. The book would be useful as a reader for an advanced beginner student.

Kurt Wiese, You Can Write Chinese, 1973 Viking Seafarer ed. (New York: 1945), p. 60. This Caldecott Honor Book written for children is not a 
language instruction book. The book is primarily written in English but does introduce 60 Chinese characters -- a surprising number for its length. The book uses traditional characters and the Wade-Giles romanization. Neither are surprising given the date of publication of the book was 1945 -- before the Chinese Revolution and the promulgation of Putonghua and pinyin.

Lee Cooper, Chinese Language for Beginners (Rutland, Vermont: Tuttle Publishing, 2002), p. 39. A very simple introduction to 39 Chinese characters uses Wade-Giles romanization. Focuses on character recognition, not writing the characters.

\section{READERS}

Shu-rong Chen, Idioms from the Classics (Taipei: Overseas Chinese Affairs Commission, 1993), p. 100. A collection of proverbs or sayings with a one page story explaining the proverb. On the left page are the Chinese characters and on the right the corresponding English translation. No romanization. For the intermediate student.

Li Lienfung, Bamboo Green (Singapore: Federal Publications, 1982), p. 149. A collection of newspapers columns from The Straits Times written in English and Chinese; the purpose of column was to improve the Chinese language skills of readers. The book displays each column in English with its Mandarin Chinese translation. The target audience is the intermediate reader.

Chung-su Tung, Chinese Fables (Taipei: Overseas Chinese Affairs Commission, 1985), p. 96. This collection of fables displays each fable (usually two pages in length) on the left page in Chinese characters and on the right the English translation and includes vocabulary with the English translation, but no romanization. Recommended for the intermediate student.

Yi-may Yang, Chinese Stories (Taipei: Overseas Chinese Affairs Commission, 1993), p. 201. A collection of short stories usually one page in length. On the left page are the Chinese characters, on the right the English translation. No romanization; for the intermediate student.

Three Hundred Poems of the T'ong Dynasty (Hong Kong: Wu Chow Publishing Co., 1982?), p. 447. A collection of Chinese classical poems with English translations. English is on the opposite page from the Chinese with punctuation so the reader can follow the translation easily. 


\section{SELF-ASSESSMENT}

Advanced Placement Exam - Chinese Language and Culture http://www.collegeboard.com/student/testing/ap/sub_chineselang.htm 1?chineselang

Part of the well-established Advanced Placement examination program for U.S. high school students, this exam was first offered in May 2007. This half-day exam will test the self-learner's reading, writing, listening and speaking skills in Mandarin Chinese. High school students can earn college credit based on their AP exam score; adult self-learners may be interested in the test to assess their skills.

Chinese Language with Listening

SAT Subject Test ese.html?chinese

http://www.collegeboard.com/student/testing/sat/lc_two/chinese/chin

This test measures listening comprehension, reading comprehension, grammar and vocabulary. The test is scored from 200 to 800 with a mean score of 758 reflecting the large number of Chinese American students taking the test. The test with the listening portion is only given in the fall.

Hanyu Shuiping Kaoshi (HSK) Test

http://www.china.org.cn/english/features/hsk/105146.htm

This official Mandarin Chinese language proficiency test is the Chinese equivalent to the Test of English as a Foreign Language (TOEFL). The various levels of this test are offered at various regional test centers in the United States. This test is probably the most effective assessment tool for the self-learner. Recommended.

\section{INTERNET SOURCES}

\section{ChinesePod}

http://chinesepod.com/

This website offers free downloads of Chinese lessons targeted at different levels of learners from Newbies to Advanced students. The lessons are very entertaining and are centered around a dialogue that is subsequently analyzed by two commentators, one a native English speaker and the other a native Mandarin speaker. Subscriptions are available for additional services such as transcripts of lessons. A popular service with nearly 100,000 subscribers. Recommended. 
MIT Open Courseware

Chinese Language Lessons

http://ocw.mit.edu/OcwWeb/Foreign-Languages-and-

Literatures/index.htm

Included in this large catalog of course materials are extensive course materials for four levels of Mandarin Chinese courses. Recommended.

Hungry for Words

https://www.hungryforwords.com/eng_default.asp

Receive via email daily words in Mandarin in subject categories such as Travel or Business and Finance. Recommended.

Dr. Tim Xie's Project and Collaborations

http://www.csulb.edu/ txie/\#Projects\%20\&\%20Collaborations:

This language professor at California State University - Long Beach includes many free web tools for learning Mandarin Chinese.

BBC Languages - Mandarin Chinese http://www.bbc.co.uk/languages/chinese/

This free web site includes a language course for beginners entitled "Real Chinese" as well as other resources for the student of Mandarin.

\section{LANGUAGE SOFTWARE}

Chinese Language Teachers Association Newsletter

This monthly newsletter has informative reviews of new books, software and web sites.

http://newsletter.clta-us.org/

CALICO Software Review

This online database maintained by the Computer Assisted Language Instruction Consortium includes reviews of Chinese language software in its LCTL (Less Commonly Taught Language) category of reviews.

https://www.calico.org/p-102-\%20LCTL.html

Wenlin

http://www.wenlin.com/

This well-known software program aids the student with its various features including an online dictionary, text editor, flash cards, and stroke by stroke animated display. 
Twinbridge Software Corporation

http://www.twinbridge.com/default.aspx

This software company offers various software tools for learning Chinese from electronic dictionaries to more complete language instruction software.

Pimsleur Language

http://www.pimsleurdirect.com/s.nl/sc.12/category.310/.f

Another well-known foreign language instruction publisher has several products for the Mandarin self-learner.

Power Chinese

Published by Transparent Language, this CD/DVD includes instruction on writing Chinese characters, Chinese vocabulary and includes frequently used words and phrases. Relatively easy to use.

Henry Raymond, Learn in Your Car in Mandarin, Penton Overseas.

This set of multiple CD's is organized into several levels of difficulty. Designed to be used solely through listening, the lessons are a series of sentences and phrases related to a particular topic. First, the speaker states an English sentence, then the Mandarin translation with time for the student to repeat the Mandarin aloud. Booklets included with the set include the dialogues with the English, pinyin and Chinese characters as well as a brief discussion of Chinese grammar. Recommended.

\section{PUBLISHERS OF CHINESE LANGUAGE SELF-STUDY MATERIALS}

Tuttle Publishing, Rutland, VT

https://peripluspublishinggroup.com/tuttle/

Penton Overseas

http://www.pentonoverseas.com/index.htm

This publisher of materials in many languages includes a significant number of Chinese language publications.

\section{China Sprout}

http://www.chinasprout.com/shop/books/learn

Distributor of Chinese language study materials 
Cheng \& Tsui, Boston, MA

http://www.cheng-tsui.com/

Based in Boston, this independent publisher sells Chinese language materials and other material related to the language and culture of Asia.

Chinese Language Teachers Association http://clta-us.org/

\section{RECOMMENDED TITLES}

The over 100 titles listed above may seem daunting. In order for the self-learner to locate a core group of relevant materials, I recommend the following titles:

Yong Ho, Chinese-English Frequency Dictionary: A Study Guide to Mandarin Chinese's 500 Most Frequently Used Words (New York: Hippocrene Books, Inc., 2002),

Yong Ho, Beginner's Chinese (New York, N.Y.: Hippocrene Books, Inc., 1997),

Philip Yungkin Lee, 250 Essential Chinese Characters for Everyday Use, vol. 1 (Rutland, VT: Tuttle Publishing, 2003).

Philip Yungkin Lee, 250 Essential Chinese Characters for Everyday Use, vol. 2 (Rutland, VT: Tuttle Publishing, 2004),

Alison \& Lawrence Matthews, The First 100 Chinese Characters (North Clarendon, VT: Tuttle Publishing, 2006),

Alison \& Lawrence Matthews, The Second 100 Chinese Characters (North Clarendon, VT: Tuttle Publishing, 2007),

Elizabeth Scurfield and Song Lianyi, Beginner's Chinese Script: An Introduction to Reading and Writing Chinese (Hodder Headline plc, 1999),

Elizabeth Scurfield and Song Lianyi, Beginner's Chinese: A Complete Course for Beginners (Hodder Headline plc, 1991),

Julie Mazel Sussman, I Can Read That: A Traveler's Introduction to Chinese Characters (China Books, 1994), 
Hong Xiao, Talk Mandarin Today / Jin ri xue shuo Putonghua (Hong Kong: Chinese University Press, 2003),

William McNaughton, Reading and Writing Chinese : A Guide to the Chinese Writing System (Rutland, Vt.: Tuttle, 1979),

Oxford Starter Chinese Dictionary (Oxford, United Kingdom: Oxford University Press, 2000),

Rick Harbaugh, Chinese Characters: a Genealogy and Dictionary (Taipei: Zhongwen.com, 1998),

Hanyu Shuiping Kaoshi (HSK) Test

http://www.china.org.cn/english/features/hsk/105146.htm

ChinesePod http://chinesepod.com/

MIT Open Courseware Chinese Language Lessons http://ocw.mit.edu/OcwWeb/Foreign-Languages-and-

Literatures/index.htm

Henry Raymond, Learn in Your Car in Mandarin, Penton Overseas.

A dedicated student who selects the recommended titles and works through them with diligence will gain some knowledge of Mandarin Chinese. Working through these materials in a thorough, consistent manner will likely take 18-24 months of diligent study. Selecting one of the self-assessment tools during this 24 month period will give the student an incentive to study and some genuine feedback on the student's progress. Good luck in your study of Mandarin Chinese. 